\title{
RADIOFUSÃO E DESENVOLVIMENTO: UMA ABORDAGEM INTRODUTÓRIA
}

\author{
Juciele Marta Baldissarelli ${ }^{1}$ \\ Levi Hülse ${ }^{2}$ \\ Adelcio Machado dos Santos ${ }^{3}$ \\ Larissa kvitko ${ }^{4}$
}

Recebido em: 20 dez. 2018

Aceito em: 08 maio 2019

\begin{abstract}
Como citar este artigo: BALDISSARELLI, Juciele Marta et al. RADIOFUSÃO E DESENVOLVIMENTO: UMA ABORDAGEM INTRODUTÓRIA. Revista Visão: Gestão

Organizacional, Caçador, SC, Brasil, p. 115-126, jun. 2019. ISSN 2238-9636. Disponível em: <http://dx.doi.org/10.33362/visao.v8i1.1874>.
\end{abstract}

Resumo: Esse estudo objetiva retratar de maneira introdutória, o papel que os meios de comunicação, mais propriamente o rádio, desempenha na sociedade proporcionando o acesso as informações. A atualidade é marcada pela era do conhecimento, e a mídia é responsável por fomentar o desenvolvimento da sociedade. Nesse sentido, as rádios proporcionam o acesso ao conhecimento com a veiculação de notícias e informações. Assim, os ouvintes tornam-se conhecedores de direitos e deveres, para que possam fazer uso e tornar o convívio com a comunidade uma obra em proveito do desenvolvimento. Desta forma, constata-se que o acesso à informação que o rádio proporciona, é importante para o progresso social e cultural de uma sociedade. A referida pesquisa, é um estudo qualitativo, bibliográfico e documental, em que foram utilizados aporte de artigos científicos e documentos relacionados ao tema.

Palavras-Chave: Comunicação. Desenvolvimento. Rádio.

RADIOFUSION AND DEVELOPMENT: AN INTRODUCTORY APPROACH

Abstract: This study aims to portray in an introductory way the role that the media, more properly the radio, plays in society by providing access to information. Today is marked

\footnotetext{
1 Doutoranda em Ciências Contábeis e Administração na Universidade Regional de Blumenau (FURB). Mestre em Desenvolvimento e Sociedade pela Universidade Alto Vale do Rio do Peixe (UNIARP). Docente nos cursos de jornalismo, farmácia, administração e sistemas de informação da Universidade Alto Vale do Rio do Peixe (UNIARP). E-mail: jucielemarta_baldissarelli@hotmail.com.

2 Doutor em Ciência Jurídica pela Universidade do Vale do Itajaí (UNIVALI), na área de concentração em Constitucionalismo, Transnacionalidade e Produção do Direito. Mestre em Ciência Jurídica pela UNIVALI. Graduado Bacharel em Direito pela Fundação Universidade Regional de Blumenau FURB (2010), e graduado em História pela Fundação Universidade Regional de Blumenau FURB (2006). Advogado com a OAB/SC 31.986. Professor na Universidade do Alto Vale do Rio do Peixe - UNIARP. O autor agradece ao Fundo de Apoio à Pesquisa (FAP) da UNIARP pelo apoio financeiro. E-mail: levi@uniarp.edu.br.

3 Doutor em Engenharia e Gestão do Conhecimento pela Universidade Federal de Santa Catarina (UFSC). Docente e pesquisador do Programa de Pós-Graduação em Desenvolvimento e Sociedade e do Programa Profissional em Educação da Universidade Alto Vale do Rio do Peixe (UNIARP). E-mail: adelciomachado@gmail.com.

${ }^{4}$ Doutoranda em Ciências Contábeis e Administração na Universidade Regional de Blumenau (FURB). Mestre em administração pela Universidade Regional de Blumenau (FURB). Docente no curso de administração da Universidade Federal Rural da Amazônia (UFRA). E-mail: kvitko.la@hotmail.com.
} 
by the age of knowledge, and the media is responsible for fostering the development of society. In this sense, radios provide access to knowledge through the dissemination of news and information. Thus, listeners become aware of rights and duties, so that they can make use of and become acquainted with the community a work for the benefit of development. In this way, it is verified that the access to the information that the radio provides, is important for the social and cultural progress of a society. This research is a qualitative, bibliographical and documentary study, in which scientific papers and documents related to the theme were used.

Keywords: Commucation. Development. Radio.

\section{INTRODUÇÃO}

Uma comunicação eficiente é o fator mais importante nas relações entre os indivíduos. O relacionamento entre as pessoas só é possível através da comunicação. Todas as esferas da atividade humana, sempre estão relacionadas com a utilização da comunicação, ela é o que conduz todas as ações do ser humano. Desde o princípio da humanidade, ela é reconhecida como um instrumento de integração, instrução, troca mútua e desenvolvimento nas sociedades.

A palavra comunicação deriva do latim comunicare e segundo Ferreira (2004), comunicar quer dizer associar, estabelecer comunicação entre; ligar, unir, compartilhar, tornar comum. Já os autores Bateman e Snell (1993, p. 402), definem comunicação escrevendo que "é a transmissão de informação e significado de uma parte para outra através da utilização de símbolos partilhados".

Uma comunicação só será eficiente se foram observados alguns pré-requisitos. Segundo Nassar (2005, p. 51), a estrutura comunicacional possui quatro características essenciais. Tais como emissor, que é quem está ligado a organização e é quem inicia a mensagem; meio ou canal de transmissão, que está ligado as ferramentas de comunicação, é o meio através do qual é transmitida a mensagem; receptor que é o público a quem a mensagem é dirigida e as respostas ou feedback que são os resultados obtidos com a comunicação.

Nesse contexto que trata da importância da comunicação, podemos abordar os meios de comunicação, mais precisamente um deles, que é o rádio. A informação é um elemento de fundamental importância, pois é por meio dela que os sujeitos se relacionam e tomam conhecimento das mais variadas informações. Desta forma, o rádio tem se despontado como um meio popular, composto por informação e entretenimento ao mesmo tempo. Mediante a essa motivação, a referida pesquisa se propõe a investigar de maneira introdutória o papel que os meios de comunicação, mais propriamente o rádio, desempenha na sociedade proporcionando o acesso as informações.

A primeira seção deste artigo, aqui concluída, destinou-se a apresentar, problematizar 
e justificar a importância do tema analisado. A segunda apresentará a revisão teórica, a terceira parte, explicará o método utilizado, bem como o perfil da população, a quarta parte está a discussão e os resultados encontrados, e por fim as conclusões do estudo.

\section{O RÁDIO COMO MEIO DE COMUNICAÇÃO}

Mesmo com toda a tecnologia existente em nosso cotidiano, o rádio continua sendo um dos principais veículos de comunicação. Ele faz parte da vida de milhares de pessoas espalhadas por todo o planeta, levando informações e entretenimento. Em função da praticidade com aparelhos portáteis, não só em casa, no carro, no trabalho pode-se ouvir rádio, mas também durante a caminhada, passeios, piqueniques, enfim em todos os lugares. Atualmente é possível ouvir rádio até mesmo nos celulares, que são a grande febre no mundo.

Desde a sua criação até agora, o rádio foi reconhecido e consagrado no início com as radionovelas, os programas de auditório e as cantoras eleitas como rainhas do rádio, as quais fizeram sucesso. Como um ícone da modernidade na década de 1950, o rádio destacou-se por ser um meio de comunicação integrador que transpôs a barreira do analfabetismo e levou informação para toda a população. Passou a fazer parte do cotidiano das pessoas e continua sendo um dos grandes veículos de comunicação que atinge todas as classes sociais.

Há mais de um século, o Padre gaúcho Roberto Landell de Moura, responsável por testar a primeira transmissão de fala por ondas eletromagnéticas sem fio, prenunciava, que os aparelhos poderiam estabelecer comunicação com quaisquer pontos da terra, por mais afastados que estivessem um dos outros (CAUSO 2003 p.125).

O rádio é um veículo de comunicação presente no Brasil desde a década de 1920 e tem resistido a presença dos avanços tecnológicos. Para Leal (1998), a função do rádio é ampla, que contempla prestação de serviços à população, distante de qualquer interferência política ou comercial. No intuito de prestação de serviços, Leal (1998), complementa que é apresentar fatos e ideias que contribuam para a prática cotidiana da cidadania.

Já Alves (2008) observa que o rádio pode ser encontrado nos locais mais antagônicos do mundo, sendo desta forma, um meio de informação fundamental e necessário para o desenvolvimento da sociedade. "Sem dúvida, ao longo da sua trajetória, esse meio de comunicação se tornou, entre todos os demais, o mais democrático e popular" (ALVES et al. 2008. p. 39).

Neste sentido, as emissoras de rádio são os principais meios de divulgação de todo e qualquer tipo de ações desenvolvidas dentro e fora do universo. Desde 1923 com o surgimento da comunicação de massa com a instalação da radiodifusão no Brasil, tendo como pioneiros Roquette Pinto e Henry Morize o assunto é debatido (ALVES et al. 2008. p. 46).

Comassetto (2007), destaca que o rádio só não continua vivo, como resiste ao tempo 
e atinge o maior número de pessoas no mundo. Para o autor, embora desafiado pelo entorno tecnológico da era contemporânea e pelo processo da globalização que se manifesta em todos os setores, o rádio deverá continuar exercendo papel relevante no contexto comunicacional (COMASSETTO, 2007, p. 25).

Ainda de acordo com Comassetto (2007, p. 66), após a chegada da televisão no Brasil no ano de 1950, o rádio precisou encontrar formas e maneiras de se adaptar a uma nova realidade. A consequência dessa reinvenção, foi a de o tornar ainda mais próximo das pessoas. "O rádio virou prestação de serviço, jornalismo local, música, companhia e diversão. Enfim, passou a ser um bom companheiro um veículo mais íntimo do cotidiano do cidadão" (COMASSETTO, 2007, p. 66).

A maneira do rádio ser, um meio simples, acessível e de baixo custo financeiro para os ouvintes, são características que fazem com que ocorra uma profunda relação com a sociedade.

\section{O PAPEL DO RÁDIO COMO MEIO DE INFORMAÇÃO}

De acordo com a Associação Brasileira de Emissoras de Rádio e Televisão (ABERT), até o ano de 2013, o rádio esteve presente em $88,1 \%$ dos domicílios do Brasil, com aproximadamente 9,4 mil emissoras em funcionamento, sendo que cerca de $80 \%$ das emissoras do país já transmitiam a programação pela internet.

O rádio é um elemento fundamental na comunicação, pois possui características de informar, distrair, permitir a participação e de fazer companhia às pessoas que buscam informação, seja ela de maneira informal, objetiva, clara ou precisa. O rádio é capaz de oferecer oportunidade de percepção dos direitos e deveres do cidadão auxiliando na formação crítica.

\footnotetext{
Entre os meios de comunicação de massa, o rádio é, sem dúvida, o mais popular e o de maior alcance público, não só o Brasil como em todo o mundo, constituindo-se, muitas vezes, no único a levar a informação para populações de vastas regiões que não têm acesso aos outros meios, seja por motivos geográficos, econômicos ou culturais (ORTRIWANO, 1995, p. 78).
}

Entre todas as suas características que o distingue como meio de informação, a instantaneidade é uma das que mais merece destaque no rádio. Parada (2000) chama atenção para o assunto, para ele diferente do que acontece em outros meios de comunicação, no rádio todos os funcionários passam a ser colaboradores, para que essa agilidade seja levada ao ar.

Numa rádio jornalística, todos os funcionários são repórteres. Este é o conceito: a reportagem envolve desde o dono da emissora até quem não está diretamente ligado à função de produzir e captar notícias. Eis a diferença entre a rádio viva e quente e a emissora anódina e burocrática. É do esforço coletivo que vem a força de um prefixo (PARADA, 2000, p. 29). 
Pensamento parecido em relação ao assunto, possuem os pesquisadores Chantler e Harris (1998, p.20). Para eles, um jornalista ao pensar em se transformar em um profissional de rádio, precisa entender a força do meio e as razões dessa potência. "Pesquisas sobre a recepção de notícias junto ao público mostram que o rádio é considerado a fonte mais pura de informações jornalísticas, e isso é atribuído à rapidez com que as notícias são transmitidas".

Os dois pesquisadores Chantler e Harris (1998, p. 21), apontam ainda outras características marcantes do rádio como meio de informação. Elas estão relacionadas especialmente a simplicidade, a falta de imagens e a identidade local que o ele possui. "Você deverá sempre empenhar-se para fazer o melhor uso possível das grandes qualidades do rádio: a velocidade e a simplicidade".

Por ser um meio que se comunica com todos os tipos de pessoas e nos mais diversos locais, o rádio nesse caso representado pelos profissionais locutor ou jornalista, torna-se íntimo dos ouvintes. É alguém do outro lado do aparelho, que sem muitas formalidades, bastando apenas o aparelho estar ligado, por intermédio das ondas entra nas casas e nos mais diversos estabelecimentos com uma mensagem informativa ou de entretenimento.

No decorrer dos anos, os pioneiros da radiodifusão brasileira criaram um slogan para nortear os rumos do rádio, sendo que Roquette Pinto (apud FERRARETTO, 2007, p. 97) declarou: "Trabalhar pela cultura dos que vivem em nossa terra e pelo progresso do Brasil". Movido pelo mesmo ideal, Roquette Pinto definiu essa função do rádio ao dizer:

O rádio é o jornal de quem não sabe ler; é o mestre de quem não pode ir à escola; é o divertimento gratuito do pobre; é o animador das novas esperanças; o consolador do enfermo; o guia dos sãos; desde que o realizem com espírito altruísta e elevado (IN FERRARETTO, 2007, p. 97).

Assim, a comunicação exercida pelo rádio, contribui para que ocorra a construção da cidadania ou de práticas de cidadania. Um cidadão mais informado, por exemplo, está mais ciente de seus direitos políticos, civis, culturais, sociais, do que aquele que não tem acesso as informações relacionadas a esses temas. Nesse contexto, Duarte (2011, p. 51) afirma que "desta forma o não-acesso à informação; o acesso limitado ou o acesso a informações distorcidas dificultam o exercício pleno da cidadania".

\section{O PAPEL DA INFORMAÇÃO PARA O CONHECIMENTO}

O jornalismo tem passado por mudanças nos últimos anos. Se anteriormente, a comunicação era considerada um simples espaço de transmissão de informação, com o desenvolvimento tecnológico e a consolidação da mídia como legítima mediadora social, o papel do jornalismo na sociedade é muito mais importante como formadora de opinião. Alguns autores, como Gomes (2004), têm considerado que é mais aconselhável tomar a comunicação 
como campo social, do que apenas conceituá-lo como meio, canal de informação.

\begin{abstract}
A imprensa de partido foi assimilada pelas novas formas da indústria da informação. Os outros dispositivos foram incorporados a um setor industrial forte e competitivo dedicado à cultura e ao entretenimento para consumo em larga escala. A indústria da informação surge quando o mundo dos negócios se dá conta de que a informação pode se transformar num negócio cujas transações não se realizam mais com corporações, mas com duas categorias, os consumidores e os anunciantes (GOMES, 2004, p. 50).
\end{abstract}

A mídia desenvolve na sociedade um importante papel como mediadora social. Ela representa para cada pessoa uma visão diferente das coisas, no entanto, mesmo que as informações não estejam ligadas, diretamente, entre os indivíduos, devido à comunicação de massa, os mesmos presenciam alguma relação entre eles e essas informações.

Segundo Bourdieu (1989, apud PEREIRA, 2004, p. 23), um campo "é um sistema de circunstâncias formado por tradições, regras e relações simbólicas, dentro das quais agem os indivíduos". Para Pereira, existem valores num campo que se determinam através do capital e da capacidade de exercer a autoridade. "Num campo existem lutas, disputas por conhecimento e reconhecimento que acabam por formar regras e costumes determinantes de um modo específico de reconstituir, simbolicamente, as circunstâncias da vida" (PEREIRA, 2004, p. 23).

Na sociedade existe uma relação entre o poder e o discurso. Para Bourdieu (1997), o papel do campo midiático interfere e subjuga os demais campos devido à determinação de suas regras. Porém, na visão de José Pissarra Esteves (1998, apud PEREIRA, 2004), a disputa de interesses e os assuntos de caráter público assumem uma dimensão simbólica por meio da discursividade. O campo midiático realiza a homogeneização social que na época pré-moderna era feita pelo religioso.

Para Adriano Rodrigues (2001), a comunicação enquanto campo surgiu na modernidade, quando a religiosidade perdeu a força da função simbólica. Dessa forma, um campo tem legitimidade porque é independente, em partes, das funções de outros campos sociais, formando assim uma hierarquia de valores. Existe, segundo o autor, uma distinção entre a legitimidade do campo da mídia (onde os valores são de transparência e da publicidade) e, por exemplo, a do campo científico (onde os valores são baseados na adaptação ao real).

Rodrigues (2001) relata que o campo da mídia não se refere a campos específicos, mas ao mundo como um todo.

Em virtude da íntima relação com a genealogia do espaço público moderno, os processos rituais do campo dos media, em vez de estabelecerem delimitados a espaços e a momentos separados, estão disseminados pelo conjunto do tecido social moderno, abrangendo assim o conjunto da experiência do mundo. (RODRIGUES, 2001, p. 157).

O campo da mídia para o autor é onde a função expressiva prevalece sobre a função 
pragmática. "É um campo em que o dizer prevalece sobre o fazer; a importância dessas funções faz com que o discurso assuma na modernidade uma posição central na estruturação do tecido social" (RODRIGUES, 2011, p.158). Porém, isso não significa que as funções pragmáticas não sejam importantes. Isso ocorre porque o discurso jornalístico se transforma em pragmático o que resulta na transformação dos acontecimentos em notícias mediadas à sociedade.

Pelo fato do campo da mídia ser formado pelas funções expressivas, que tem como objetivo atribuir valores ao tecido social, faz dele um campo constituído por reflexos de perspectivas que acaba integrando a sociedade moderna. Dessa forma, a sua estrutura é espetacular, ou seja, se as funções expressivas da sociedade moderna regulam-se pela predominância do discurso midiático, nesse discurso a lógica é chamar a atenção do público. Para tal, a forma discursiva encontrada (linguagem) é o espetáculo.

Para Gomes (2004), o jornalismo é considerado campo quando o trabalho é realizado por profissionais competentes, capazes de produzir boas informações para se estabelecer em um patamar onde haja autoridade jornalística, credibilidade, reconhecimento, audiência, acúmulo de capital simbólico entre outras.

(...) O jornalismo enquanto sistema de relações, é também um sistema de reconhecimentos - que são oferecidos naturalmente em função de posse do capital típico do campo social. Reputação, prestígio autoridade, competência - ou reconhecimento da ausência disso tudo - são formas de distinção que se aplicam tanto aos indivíduos, os jornalistas, quanto às instituições (....) (GOMES, 2004, p. 54).

Na definição de campo, o jornalismo é sistema social, ou seja, as informações são repassadas de acordo com os interesses da sociedade, porém as estratégias de comunicação, e as decisões são escolhidas de acordo com interesses dos agentes jornalísticos tendo sempre principal objetivo a conquista de credibilidade.

(...) O jornalismo é um sistema social e os jornalistas são agentes, ocupando posições diferenciadas, buscando em lutas concorrenciais internas acumular o capital simbólico que o campo distribui, deixando com que preocupações com reputação e prestígio jornalístico orientem suas escolhas dirijam suas atitudes e constituam seus valores (GOMES, 2004, p. 57).

O contrário acontece quando o jornalismo é considerado um meio, ou seja, quando possui dependência financeira em relação à política, economia, etc. Ele é comandado por um outro campo que tem interesse em fazer com que a mensagem desejada chegue à sociedade. Na visão de Gomes (2004), o jornalismo é considerado meio, quando o veículo de comunicação depende da venda de espaços publicitários, do poder político, onde a circulação de mensagem política ganha cada vez mais espaço e o poder econômico exerce influência editorial.

Já a comunicação de massa, segundo o autor, caracteriza-se por três fenômenos. 0 primeiro é as formas expressivas dos processos da comunicação midiática, incluindo a comunicação pela televisão e via internet. 
O segundo refere-se aos meios técnicos, responsáveis pela transmissão de informações em larga escala e alcance indefinido. "(...) Incluem desde os recursos voltados para o domínio do aparato tecnológico até o controle das formas expressivas (linguagens) específicas da comunicação de massa" (GOMES, 2004, p. 62).

Finalmente, o terceiro fenômeno são os meios institucionais responsáveis pela produção da comunicação de massa. "(...) Incluem desde os ambientes profissionais, os campos da realização, até o sistema dos agentes envolvidos e as empresas dedicadas à produção e emissão dos conteúdos que circulam nos meios técnicos" (GOMES, 2004, p. 62).

Na opinião de Gomes (2004), a comunicação hoje não pode ser considerada mais como meio. "(...) as instituições da comunicação e a cultura de massa há muito deixaram de ser meio entre duas coisas, tendo-se constituído em sistemas consideravelmente autônomos" (GOMES, 2004, p. 60).

\section{A NECESSIDADE DO CONHECIMENTO PARA O DESENVOLVIMENTO}

Quando abordamos questões relacionadas ao desenvolvimento de uma sociedade, por diversas vezes esse desenvolvimento é confundido apenas como econômico. No entanto, é necessário ressaltar que uma sociedade desenvolvida não está unicamente atrelada a questões financeiras, mas também a sua cultura e o social. De acordo com Cardoso, essa é a justificativa para a existência do desenvolvimento.

Deve-se valorizar a definição autônoma de estilos de desenvolvimento e vida, que estimulem a criatividade e conduzam à melhor utilização dos fatores de produção, diminuam a vulnerabilidade e a dependência, de tal modo que as sociedades contem mais com suas próprias forças de resistência, confiem em si próprias e tenham meios para serem dignas (CARDOSO, 1980, p. 38).

Pessoas mais cintes de seus deveres e direitos, mais informadas sobre os diversos assuntos que as cercam e as interessam, seja do cotidiano local ou atrelado ao mundo, possuem melhores condições de se desenvolverem profissionalmente e pessoalmente. Nesse contexto, Pereira (1985) explica que desenvolvimento está relacionado a uma transformação global.

Desenvolvimento é um processo de transformação econômica, política e social, através do qual o crescimento do padrão de vida da população tende a tornar-se automático e autônomo. Trata-se de um processo social e global, em que as estruturas econômicas, políticas e sociais de um país sofrem contínuas e profundas transformações. Não tem sentido falar-se em desenvolvimento apenas econômico, ou apenas político ou apenas social. Na verdade, não existe desenvolvimento dessa natureza, parcelado, setorializado, a não ser para fins de exposição didática. O desenvolvimento, portanto, é um processo de transformação global (PEREIRA 1985, p.19). 
Ainda na mesma linha de pensamento, Melo (1989), também destaca que desenvolvimento vai além de uma questão financeira, trata-se de um processo contínuo de libertação dos povos e da sociedade, em que estes são capazes de afirmar sua autonomia e, com autoconfiança, incrementar atividades de seu interesse (MELO 1989, p. 56).

A relação entre a comunicação e desenvolvimento, é um assunto relevante, pois é por meio da comunicação, que o homem se torna um ser social ao realizar a transmissão de suas ideias. Em casa, no trabalho, na escola, com os amigos, a comunicação possui papel fundamental para que ocorra o desenvolvimento, pois é por ela que as pessoas são entendidas e entendedoras. Conforme destaca com Steinberg (1986, p. 23), sem a comunicação, os homens não poderiam ajuntar-se, empreender tarefas conjuntas, nem progredir no domínio do mundo físico. Visto que as invenções e descobrimentos dependem quase sempre de uma acumulação de informações e de um gradativo desenvolvimento de conceitos transmitidos de uma geração à seguinte.

Com o rádio, como meio de comunicação, acontece a mesma relação. Se no princípio dos tempos, uma notícia precisava meses para chegar aos locais mais longínquos, hoje com o rádio não demora mais que segundos. O produto dessa comunicação, que é a fala, tem valor indiscutível, desempenhando sempre um papel fundamental nos processos, colaborando para a integração e tornando-se o meio de comunicação mais popular e de maior alcance, em termos geográficos, culturais ou econômicos.

De acordo com McLuhan "o rádio afeta as pessoas, digamos como que pessoalmente, oferecendo um mundo de comunicação não expressa entre o escritor-locutor e o ouvinte. Este é o aspecto mais imediato do rádio. Uma experiência particular" (MCLUHAN 1964, p. 336).

Os adventos da comunicação desde o surgimento da primeira a palavra escrita formalizada por meio da imprensa na segunda metade do século XV, a palavra falada através da radiodifusão no final do século XIX, o som aliado à imagem com o surgimento da televisão no início do séc. XX e agora com a internet, tem auxiliado no desenvolvimento da comunicação. Essa evolução nos leva à compreensão de que não existiria sociedades evoluídas e globalizadas, sem esse avanço da comunicação.

Os meios de comunicação possuem responsabilidades no processo da convivência e do desenvolvimento humano. O rádio, por ser um meio de baixo custo, acessível e sem exigências, como é o caso dos jornais em que a pessoa precisa saber ler para se informar, está acessível ao maior número de indivíduos em uma sociedade. Essa escrita que é "falada" e "oralizada", é a maneira que o rádio tem para se expressar, para se relacionar com o outro e de perceber o mundo na sua globalidade, em que espaço real e distância vão se tornando cada vez mais irrelevantes.

Meditsch propõe uma reflexão acerca disso.

[...] Ninguém dúvida da importância do rádio hoje na sociedade brasileira, nem de sua 
capacidade de influenciar o comportamento das pessoas, de criar novos hábitos de consumo e de atender as demandas simbólicas por lazer, entretenimento, informação e companhia (MEDITSCH, 1998, p.17).

Sendo assim a comunicação, por meio dos veículos de comunicação, deve entender que colocar esforços para investigar ou alterar a realidade social brasileira não é mais uma questão de opção, mas um imperativo para a sobrevivência do país. Para o bem de uma sociedade, as pessoas devem aprender e ter a condição de acompanhar as mudanças e avanços cada vez mais rápidos. O papel da mídia é informar, ajudando a sociedade a saber, conhecer, pensar e agir.

\section{CONSIDERAÇÕES FINAIS}

Características como a instantaneidade, a aproximação, a identificação com o ouvinte, baixo custo e fácil acesso, fazem com que o rádio seja considerado um meio de comunicação de massa, ou seja, disponível a grande maioria das pessoas. A radiodifusão confunde-se com a própria vida, tornando-se uma necessidade humana e, mais do que nunca, preenchendo uma lacuna, pois o rádio, com sua facilidade de acesso chega aos locais mais longínquos.

É pelo rádio que são anunciadas primeiramente a maior parte das informações, repercutidas posteriormente pelos demais meios, como a televisão, jornais e revistas. É um poderoso elo com a comunidade, oferecendo entretenimento, informação e articulação em prol do desenvolvimento da sociedade em que está sendo ouvido.

Desta maneira, o significado de desenvolvimento não está relacionado apenas as questões financeiras e de progresso material. Assim, pode-se constatar que essa explicação é mais ampla. Nessa pesquisa introdutória, procurou-se oferecer alguns subsídios informativos para que ocorra esse entendimento. E constatou-se que o termo "desenvolvimento" não significa somente o aumento da economia, sendo está apenas mais uma etapa que o envolve, inclusive, a melhoria das condições de vida da população.

Nesse sentido, pode-se afirmar que os meios de comunicação e nesse caso o rádio, influencia no desenvolvimento não apenas no âmbito econômico, mas especialmente na área social e cultural. Assim, conclui-se que a resposta ao questionamento inicial desta pesquisa não se esgota em si mesma. Conforme já citado, essa é uma pesquisa inicial, sendo que deixa em aberto a possibilidade de que mais interessados se apropriem do tema e aprofundem o estudo.

\section{REFERÊNCIAS}

ABERT. Disponível em: <http://www.abert.org.br>. Acesso em: 13 nov. 2015.

ALVES, MARCIA NOGUEIRA; FONTOURA, MARA; ANTONIUTTI, CLEIDE LUCIANE. Mídia e 
produção áudio visual: uma introdução. Curitiba: IBPEX, 2008.

BATEMAN, Thomas S. \& SNELL, Scott A. Administração: construindo vantagem competitiva. São Paulo: Atlas, 1998.

BOURDIEU, Pierre. O poder simbólico. Rio de Janeiro, Bertrand Brasil, 1989.

CARDOSO, Fernando Henrique. As idéias e seu lugar - ensaios sobre as teorias do desenvolvimento. Petrópolis: Vozes, 1980.

CÉSAR, Cyro. Como falar no Rádio - prática de locução AM e FM. São Paulo: Summus editorial, 2009.

CAUSO, ROBERTO DE SOUSA. Ficção científica, fantasia e horror no Brasil, 1875 a 1950. Belo Horizonte: Editora UFMG, 2003.

DUARTE, Dorival. RÁDIO SANTA CRUZ: Estudo das contribuições da radiodifusão à região do Vale do Rio Pardo. Disponível em: <http://btd.unisc.br/Dissertacoes/DogivalDuarte.pdf>. Acesso em: 13 nov. 2015

ESTEVES, João P. A ética da comunicação e os média modernos. Lisboa: Fundação C. Gulbenkian, 1998.

FERREIRA, Aurélio Buarque de Holanda., 1910-1989. Minidicionário: o minidicionário da língua portuguesa. [et. al.]. 6. ed. rev. atualiz. Curitiba: Positivo, 20014.

GOMES, Wilson. Transformações da política na era da comunicação de massa. São Paulo: Paulus, 2004.

FERRARETO, L. A. Rádio: o veículo, a história e a técnica. 2. ed. Porto Alegre: Sagra Luzzatyo, 2001.

LEAL, M. Cristina. Nas ondas da razão e da ciência: a radioeducação como instrumento da modernidade no Brasil dos anos 20 aos 50. Moderna OnLine. Fazendo Escola. Disponível em: <http://www.moderna.com.br/escola/prof/art64.htm>. Acesso em: 13 nov. 2015.

MCLUHAN, Marshall Herbert. Os meios de comunicação como extensão do homem. São Paulo: Cutrix, 1964.

MELO, José Marques (Org.). Comunicação na América Latina: Desenvolvimento e crise. Campinas, SP: Papirus, 1989.

NASSAR, Paulo \& FIGUEIREDO, Rubens. O que é comunicação empresarial. São Paulo: Brasiliense, 2007.

ORTRIWANO, Gisela Swetlana. A Informação no Rádio - os grupos de poder e a determinação dos conteúdos. São Paulo: Summus, 1985. 
PARADA, Marcelo. Rádio: 24 horas de jornalismo. São Paulo: Panda, 2000.

PEREIRA, Luiz Carlos Bresser. Desenvolvimento e crise no Brasil 1930-1983. São Paulo:

Brasiliense, 1985.

PEREIRA, Marcos Vinícius. A espetacularização da política no "cidade viva". Porto Alegre, 2004. 206p. Dissertação (Mestrado) - Curso de Pós-Graduação em Comunicação e Informação.

UFRGS. Universidade Federal do Rio Grande do Sul.

RODRIGUES, Adriano Duarte. Estratégias da comunicação questão comunicacional e formas de sociabilidade. Lisboa: Presença, 2001.

RUAS, Cláudia Mara Stapani. Rádio Comunitária: uma estratégia para o desenvolvimento. Campo Grande: Editora UCDA, 2004.175 p.

STEINBERG, Charles S. (org.). Meios de comunicação de massa. São Paulo: Cultrix, 1966. 